\title{
Barriers to access for severe acute malnutrition treatment services in Pakistan and Ethiopia: a comparative qualitative analysis
}

\author{
Chloe Puett $^{1, *}$ and Saul Guerrero ${ }^{2}$ \\ ${ }^{1}$ Action Against Hunger (ACF-USA), 247 West 37th Street, New York, NY 10018, USA: ${ }^{2}$ Action Against Hunger \\ (ACF-UK), London, UK
}

Submitted 17 April 2014: Final revision received 26 September 2014: Accepted 1 October 2014: First published online 13 November 2014

\begin{abstract}
Objective: To understand and compare the primary barriers households face when accessing treatment for cases of childhood severe acute malnutrition (SAM) in different cultural settings with different types of implementing agencies.

Design: The study presents a comparative qualitative analysis of two SAM treatment services, selected to include: (i) one programme implemented by a nongovernmental organization and one by a Ministry of Health; and (ii) programmes considered to be successful, defined as either coverage level achieved or extent of integration within government infrastructure. Results from individual interviews and group discussions were recorded and analysed for themes in barriers to access.

Setting: Sindh Province, Pakistan; Tigray Region, Ethiopia.

Subjects: Beneficiary communities and staff of SAM treatment services in two countries.

Results: Common barriers were related to distance, high opportunity costs, knowledge of services, knowledge of malnutrition and child's refusal of ready-touse foods. While community sensitization mechanisms were generally strong in these well-performing programmes, in remote areas with less programme exposure, beneficiaries experienced barriers to remaining in the programme until their children recovered.

Conclusions: Households experienced a number of barriers when accessing SAM treatment services. Integration of SAM treatment with other community-based interventions, as the UN recommends, can improve access to life-saving services. Efforts to integrate SAM treatment into national health systems should not neglect the community component of health systems and dedicated funding for the community component is needed to ensure access. Further research and policy efforts should investigate feasible mechanisms to effectively reduce barriers to access and ensure equitable service delivery.
\end{abstract}

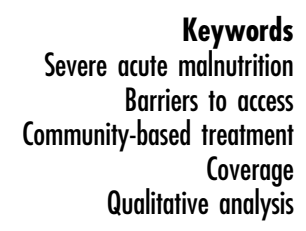

Access to effective health care is a significant problem in developing countries. While millions die from preventable diseases, large health gains could be achieved if access and utilization of existing effective interventions were improved $^{(1,2)}$. This situation persists due to the existence of numerous interrelated barriers on both the demand and supply side, which limit access to services. Supply-side barriers are those related to service provision and include location of services, availability of personnel and supplies, technology used and cost of services. Demand-side barriers are those affecting a household or community's ability to utilize services and include distance to services, cultural preferences, education and household resources ${ }^{(3-5)}$. Demand-side constraints are as influential as supply-related factors in preventing households from accessing services ${ }^{(6)}$.
Severe acute malnutrition (SAM) has gained recognition as an important public health concern. In recent years, effective community-based protocols known as the community-based management of acute malnutrition (CMAM) ${ }^{(7,8)}$, including use of ready-to-use therapeutic foods (RUTF), have improved access to treatment, and there is an increasing focus on integrating treatment into national health services delivered by ministries of health $(\mathrm{MoH})^{(9,10)}$.

Although CMAM programmes are implemented in many countries, there remain large gaps in coverage ${ }^{(11)}$. Information on the barriers to access to SAM treatment is limited; however, there is a growing body of evidence. One previous study provided evidence on barriers experienced by households in five African countries when accessing vertical services delivered primarily by non-governmental 
organizations $(\mathrm{NGO})^{(12)}$. That study found the three most common barriers to be distance to sites, community awareness and handling of rejections by community-based staff. Other barriers included high opportunity cost of caregivers' time, lack of child care for other siblings and harvest obligations. More recent evidence comes from a communitybased integrated programme in Bangladesh using NGOsupported community health workers to provide community case management of SAM at village level along with other curative and preventive care ${ }^{(13)}$. Findings from that study indicated that integrating SAM treatment into a broader package of community-based services successfully addressed a number of common barriers to access, including distance along with awareness and acceptability of services to caregivers of children with SAM. Coverage in the latter programme was among the highest achieved to date by a CMAM programme $^{(14)}$. Taken together, findings from these studies suggest that as service delivery mechanisms evolve, barriers related to household factors are persistent (e.g. high opportunity costs for resource-poor households) whereas barriers related to programme factors (e.g. distance to site, community sensitization efforts, interface between staff and community) can be mitigated by adjusting service delivery mechanisms.

While previous research has found that lack of community awareness is a major barrier to access to SAM treatment services and that comprehensive community-based sensitization mechanisms can successfully address this barrier, the community elements of sensitization, mobilization and follow-up have not been consistently or successfully implemented when integrating CMAM into national health systems ${ }^{(15)}$. Discussion with communities about the barriers they face in accessing services provides important information about acceptability and accessibility of evolving service delivery mechanisms. The Coverage Monitoring Network is an inter-agency partnership established in 2012 to measure and track community access to CMAM programmes through supporting coverage evaluations and assessing barriers to access in programmes around the world. The present study, supported by the Coverage Monitoring Network, presents a comparative qualitative assessment of two SAM treatment services: (i) an NGO-implemented service in Pakistan; and (ii) a service integrated into $\mathrm{MoH}$ infrastructure in Ethiopia.

The objective of the analysis was to understand and compare the primary demand-side barriers to accessing effective SAM treatment services faced by households in two different cultural settings, with different types of implementing agencies. Selecting effective programmes aided in controlling as much as possible for supply-side constraints, enabling the analysis to focus on demand-side barriers to access.

\section{Methods}

Qualitative methods were used to assess and compare barriers to access faced by households in two programmes.

\section{Selection of intervention}

Members of the Coverage Monitoring Network selected the two programmes using two criteria: (i) one programme should be implemented by an NGO and one by the MoH; and (ii) the programmes should be considered 'successful'. Success was defined as either the extent of coverage level in a recent assessment or the extent of integration achieved within $\mathrm{MoH}$ infrastructure.

\section{Description of context and interventions}

\section{Ethiopia}

Tigray Region, situated in northern Ethiopia, is primarily a highland region divided into western lowlands and central highlands with sparsely populated, mountainous terrain. Major livelihoods are livestock and farming, with primary crops of teff, wheat and barley ${ }^{(16)}$. Agriculture is dependent on the annual kiremti rains between April and August. An annual hunger gap occurs between June and September. The primary ethnic group is Tigrinya and the primary religion is Orthodox Christian. While Tigray has a relatively high overall literacy rate, literacy levels among rural women have been estimated at less than $20 \%{ }^{(17)}$.

The programme in Ethiopia was part of the Health Extension Programme implemented by the national health system. In Tigray the Health Extension Programme was supported by Concern Worldwide at different levels in different woredas (districts). Services were delivered both at community-level health posts providing basic services and at district-level health centres. The programme used a two-tier system of community health workers. Health extension workers (HEW) were formal salaried workers within the health system, with over 30000 deployed throughout Ethiopia. Two HEW served each health post, situated at the kebele level (sub-district or ward) and serving a population of approximately 5000 individuals $^{(18)}$. HEW were required to have at least a tenth grade education and received 1 year of professional training for the position. HEW provided treatment for SAM as part of a bundle of services containing sixteen packages on topics such as hygiene, family health, disease prevention and control, and health education. The Women's Development Army (WDA) was a team of community-level volunteers, also recognized within the health system and engaged in screening children under 5 years old in thirty households in their villages. Children under 2 years old were screened at monthly growth monitoring and promotion sessions and children under 5 years old at Community Health Days, held every 3 months. This programme was included in the analysis due to its strong level of integration within the national health system.

\section{Pakistan}

Sindh Province is located in southern Pakistan near the border with India. It is bordered by desert to the east and the Arabian Sea to the south, with a central fertile plain 
Table 1 Number and type of respondents per country

\begin{tabular}{|c|c|c|c|c|}
\hline \multirow[b]{2}{*}{ Respondents } & \multicolumn{2}{|c|}{ Ethiopia } & \multicolumn{2}{|c|}{ Pakistan } \\
\hline & Focus group discussions & Individual interviews & Focus group discussions & Individual interviews \\
\hline Programme staff & & 13 & 6 & \\
\hline Communities & 4 & 7 & 3 & \\
\hline \multicolumn{5}{|l|}{ Beneficiaries } \\
\hline Recovered & & 16 & & 11 \\
\hline Defaulted & & 21 & & 10 \\
\hline Non-beneficiaries & & 1 & 2 & \\
\hline
\end{tabular}

around the Indus River. Agriculture is the primary livelihood, and due to local land ownership practices there is a large migrant labourer population ${ }^{(19)}$, including in particular minority Hindu castes such as the Koli. Staple crops include wheat and rice. An annual hunger gap occurs between July and September. The area receives light winter rains typically between December and February, and heavier rains in the monsoon season between July and September, which sometimes cause intensive flooding ${ }^{(20)}$. High temperatures occur from June through August and some areas are prone to drought. The region suffers from limited rural infrastructure, including poor roads which are washed out during the rains. Islam is the primary religion. Female literacy is low in rural Sindh Province, at $22 \%{ }^{(21)}$.

The programme in Pakistan, implemented by Action Against Hunger (ACF-USA), had out-patient therapeutic programme (OTP) sites at eleven out of sixteen Union Councils (UC; sub-districts) within Tando Mohammed Khan and Badin districts of Sindh Province. On average, UC have a population size of approximately 35000 individuals. Three programme staff in each UC provided SAM treatment services weekly at the OTP site and relied predominantly on community nutrition volunteers for screening, sensitization and following up absentees. Volunteers were respected community members who were literate and numerate, and each had a catchment area of approximately five villages (1500-2500 total population), typically within $5-10 \mathrm{~km}$ from their homes. In each UC, OTP services were delivered from one static site and two satellite sites selected based on beneficiary location, to bring services closer to the community. This programme was included in the analysis due to its relatively high 'period' coverage (i.e. an estimation of coverage in a given, recent period ${ }^{(22)}$ ) of $62 \cdot 6 \%^{(23)}$.

\section{Instruments and study participants}

To get different perspectives on barriers, focus group discussions and individual interviews were conducted with a variety of stakeholder groups including programme staff, communities (including community leaders and other community members) and households with a child who had recently attended the CMAM programme and had been classified as either recovered from SAM or defaulted. Table 1 outlines the number of focus group discussions and individual interviews conducted with different respondent types in each country.

During household visits, discussions were held with beneficiaries regarding the barriers they faced in accessing SAM treatment services. Up to two barriers were recorded per beneficiary.

Quantitative information was also collected in these household visits via a short survey, including information on the child (age, sex), treatment received (clinical outcome, length of stay, other clinical care received) and household typology, based on factors predicted to be associated with limiting access to services, including education and occupation of parents/caregiver, ethnicity and religion, household size, distance to programme and proxies for socio-economic status (land ownership, roof material, electricity). This quantitative information was used to complement description of the qualitative findings on barriers and only when specific points could be better illustrated with quantitative data.

\section{Sampling and participant selection}

Three programme areas were selected in each programme: UC in Pakistan and woredas in Ethiopia. Programme areas and OTP sites within them were purposively selected to capture a variety of programme environments, based on criteria including agricultural and topographical characteristics, population density, implementation duration, sitespecific default rates and technical support received. In Ethiopia's Tigray Region, woredas within and bordering Central Zone (including one woreda in North-west Zone) were selected for having high variation in defaulting rates.

Within each site, a minimum of ten beneficiaries were consulted. Households of children who had recovered from SAM were randomly selected where possible using registration records. Defaulter households were purposively selected in each area; efforts were made to locate all households that had defaulted, either in the past 2 years or since the beginning of the programme, whichever was greater. A total of twenty-one defaulters were consulted in Ethiopia and ten in Pakistan.

In Ethiopia, community-based $\mathrm{MoH}$ staff were busy during the first round of data collection. Therefore data collection was extended and more beneficiary households were consulted. In Pakistan, the sample included represents the characteristics and barriers of the general programme beneficiaries. 


\section{Data collection}

Data were collected in May and June 2013. Individual and group discussions were facilitated by the researcher using a translator. Informed consent was obtained from all respondents before beginning discussions.

\section{Data analysis}

Qualitative data were analysed for themes using Microsoft ${ }^{\circledR}$ Word. Transcriptions of discussions were categorized using provisional codes for barriers from the Coverage Monitoring Network database and other themes emerging from the analysis $^{(24)}$. Categorized data were analysed for themes related to similarities and differences in demand-side barriers within each country and between the two programmes. Major themes emerging from discussions were selected for further analysis; these themes constitute the most commonly cited and therefore the most 'significant' demand-side barriers encountered in the two programmes. Quantitative data on beneficiary characteristics were analysed in Microsoft ${ }^{\circledR}$ Excel to facilitate comparisons within the small sample of households consulted for the study. These data are presented in the online supplementary material.

\section{Reliability and validity}

The study team sought to achieve reliable representation of household barriers by interviewing as many defaulting households as possible at each site. Internal validity was ensured by triangulating themes among discussions with different types of respondents (i.e. beneficiaries, community members and programme staff). Face validity of the findings was strengthened by using qualitative methods, which are appropriate for assessing community perceptions, and by conveying respondents' perceptions in their own words.

\section{Results}

Analysis of demand-side barriers to access produced several themes related to similarities and differences between the two programmes.

\section{Distance}

Distance was a commonly cited barrier and could be complicated by cultural factors, topography, road quality, lack of transportation options and weather, particularly during the rainy season or extreme temperatures. Beneficiaries often discussed distance in terms of travel time. The definition of how far was 'too far' varied by caregiver. Some caregivers declared that $1 \mathrm{~h}$ was too far, while those living 3-4 h from the site consistently found distance to prevent regular attendance. In general, caregivers reporting this barrier cited an average distance of $2 \mathrm{~h} 20 \mathrm{~min}$.

\section{Ethiopia}

Perception of distance was not consistent across households. When other domestic responsibilities were very time-consuming, even a shorter walk to the programme site was considered too far. All defaulters in Ethiopia citing distance as a barrier came from a mountainous and remote rural woreda with an average walk of $3 \mathrm{~h}$ :

'My husband went to Amhara and no one was responsible for the cattle at home, so they may be starved. As I am also responsible for the elderly at home, no one can help with my chores.' (Beneficiary, defaulter, Ethiopia)

'Having long distance is the main factor for defaulting mothers because a large number of mothers walk 4 hours to get to the OTP site.' (WDA member, Ethiopia)

'Some people walk 6-7 hours round-trip to fetch water. So there is no time to go to OTP.' (Community leader, Ethiopia)

\section{Pakistan}

Weather posed a particular problem in the Sindh Province of Pakistan, which experiences both flooding and high temperatures. Walking to the OTP posed a challenge to both caregivers and the children they carried:

'The road is not good, and we have to cross water... With a better road, we could come on time.' (Beneficiary, defaulter, Pakistan)

"We face a difficulty to come because the site is so far from our house [3 hours]. I never come alone without my husband; when the site was closer I would come with other women. During the rainy season, the road is slippery and even flooded. There is also a distance problem, during the walk we feel exhausted, and we also carry the children.' (Beneficiary, defaulter, Pakistan)

'Distance is a problem all times of year, but mostly in the rainy season. There is no proper transport, only rickshaw. There is no proper road.' (Community leader, Pakistan)

'Villages [which are] so far from this site, we have screened them, but then when the rainy season comes, people can't come easily.' (Community nutrition volunteer, Pakistan)

In Pakistan, some women were forbidden to leave the home unless accompanied by a male relative, which limited both their access to services and the ability of predominantly male programme staff to access their households for screening:

'Males are not at home so we can't go on our own to far places.' (Beneficiary, defaulter, Pakistan)

'The women remain [with]in the boundary wall of the home, this is a big challenge.' (Programme staff, Pakistan) 
One explanation was a perceived risk to female caregivers of travelling far:

'If [the programme] were nearer to our village it would be good. We come here because we are compelled for the sake of our child. A site nearby our home would be better, for privacy, women shouldn't be so exposed.' (Beneficiary, recovered, Pakistan)

\section{High opportunity costs}

Dedicating time to treatment-seeking forced caregivers to forego other important competing demands and the perceived importance of these foregone alternatives, or the 'opportunity cost' to the caregiver, was often substantial. Regular attendance was complicated by other pressing responsibilities, including harvesting fields, caring for other family members (including the elderly and other children at home), tending cattle and walking long distances to fetch water.

\section{Ethiopia}

Attendance was most difficult during the harvest season, when opportunity costs are highest, particularly for households dependent on agriculture and daily labour for their livelihoods:

'Since it was the harvest time we went to harvest and did not get adequate time to bring our child.' (Beneficiary, defaulter, Ethiopia)

'I did not go because I was busy on the farm land, preparing for summer.' (Beneficiary, defaulter, Ethiopia)

'Harvest time is the most busy time for the rural people.' (WDA member, Ethiopia)

Some children required additional treatment while they were severely acutely malnourished. The accumulated direct and indirect costs for their child's illness had an impact on parents' livelihoods, particularly if in-patient care was required:

'I closed my shop because I went to Adwa for treatment [at the Therapeutic Feeding Unit]. My livelihood was weakened. I give priority to my child and work less, my shop is almost closed. Before, I would make 100 birr profit per day if the market was fine.' (Beneficiary, recovered, Ethiopia)

\section{Pakistan}

Waiting at the OTP site took up to $1.5 \mathrm{~h}$, particularly in Pakistan where OTP sites served a large geographic area. Community members living further away would sometimes travel in groups and share a rickshaw fare, thus adding extra costs to their visit. Defaulting was higher among the Koli caste of Hindus, who would migrate from one area to another throughout the Sindh during the harvest season. This led to seasonal variation in access for this group:

'In our home there was no rice, no wheat, so we went to another city for harvesting. We mostly migrate for wheat, also during the rainy season... If we don't go, our child will die [due to lack of food].' (Beneficiary, defaulter, Pakistan)

'We are migrating and the programme is not migrating [with us].' (Beneficiary, defaulter, Pakistan)

'We are poor and we are doing harvest for daily wages, earning for home and family.' (Beneficiary, recovered, Pakistan)

As in Ethiopia, family resources were stretched thin by the intensive costs of in-patient treatment, endangering a household's ability to dedicate further time to seeing their child fully recover through out-patient care:

'We took our child to a doctor to receive treatment for cholera. We went to the doctor every day for 15 days. It was 25 minutes each way and the rickshaw cost 20 Rs. We paid 1000 Rs on a daily basis for medications, IV solutions for dehydration, and doctor's fees. On the last day, we didn't pay for rickshaw fare, and the doctor didn't forgive us the fees. We walked home. We sold all our goats and our gold for the health of our child. After recovering from cholera, the child was admitted to the OTP.' (Beneficiary, recovered, Pakistan)

\section{Knowledge of services}

The existence of health infrastructure and the level of integration into this infrastructure appeared to increase awareness of and promote access to CMAM services in different ways.

\section{Ethiopia}

Recognition of community-based workers by the health system lent the programme authority and credibility among communities:

'Since we got the [RUTF] for free, I see that the government gave me a child again. My child was critical at that time.' (Beneficiary, recovered, Ethiopia)

'We are strictly following the government's order, because our government is improving our health and child's health.' (Beneficiary, recovered, Ethiopia)

Further, some of the woredas under analysis had OTP sites at all health posts. Due in part to this decentralized service provision, and also to effective sensitization from programme staff, beneficiaries living far from a particular 
OTP site were able to find another site that was closer to their home:

'People living in this kebele who are far away, they can use a health post or health centre that is closer to them.' (Group discussion with recovered beneficiaries, Ethiopia)

\section{Pakistan}

In Pakistan, despite sensitization from community nutrition volunteers and links with government health workers, several beneficiaries recommended to increase awareness of the programme. Programme staff felt that there were certain groups of community members having limited awareness, including migrant workers or those living at a distance from the OTP site:

'These kinds of activities should be running throughout the whole community.' (Beneficiary, recovered, Pakistan)

'Do awareness-raising in all areas to increase awareness of the programme.' (Beneficiary, defaulter, Pakistan)

'Those who are living far from site have less awareness.' (Programme staff, Pakistan)

\section{Knowledge of malnutrition}

In Ethiopia, community members and staff exhibited a comprehensive understanding of child health and nutrition, including the importance of breast-feeding, complementary feeding and personal/environmental hygiene. Community awareness was further enhanced through involvement of local leaders. In Pakistan, knowledge of nutrition was restricted by limited exposure to public services and to basic education.

\section{Ethiopia}

Comprehensive knowledge of malnutrition helped to ensure that caregivers knew how to protect their child's nutrition status using local foods, rather than relying on RUTF:

'Sometimes there was an interruption of supply. I prefer to give my child complementary food at home until they bring more RUTF.' (Beneficiary, recovered, Ethiopia)

'The main point I learned is that RUTF is not enough. I need to also feed complementary foods. I hope if I feed her enough, my child will be freed from malnutrition.' (Beneficiary, defaulter, Ethiopia)

'They strictly counsel us on how to prepare complementary feeding. OTP is the last option. If you provide proper care at home, you won't need to visit the health facility because your child will be well.'
(Group discussion with recovered beneficiaries, Ethiopia)

Still, sensitization of communities did pose a challenge in some areas, and beneficiaries were not always aware of the causes and consequences of malnutrition:

'My child looks OK to me, but not to you!' (Beneficiary, defaulter, Ethiopia)

'It is best to raise the community awareness... Even though the health extension workers are working hard, it is difficult to improve community knowledge in a short period of time.' (Community leader, priest, Ethiopia)

'Awareness is a major issue, about malnutrition, why it is bad, how to prevent it. People think their child is OK.' (Director of health centre, Ethiopia)

\section{Pakistan}

One factor affecting awareness was limited exposure to public services. In Pakistan, there were few other public health programmes operating in the CMAM programme area to address important local health concerns, including immunization and potable water. Additionally, weak educational infrastructure led to limited awareness about the benefits of health, hygiene and nutrition, and the importance of following programme protocols. Sensitization was a particular challenge in these areas:

'Illiteracy is a main problem. People are not coming every 2 weeks [to the programme], because they don't take these things seriously... There are no vaccines, no potable water, no awareness of family planning. This has an effect on nutrition.' (Community leader, Pakistan)

'Polio teams are coming, but communities don't bring children to the site, they have to go to their households [to deliver treatment]. This is ignorance. Communities think there is no benefit... We give examples of someone who had polio or malnutrition and they were cured by the programme or they suffered without it. By continued follow-up and mobilization, we are able to convince people.' (Community nutrition volunteer, Pakistan)

\section{Child's refusal of ready-to-use therapeutic foods}

In Ethiopia, nearly $30 \%$ of defaulters cited children's refusal to consume RUTF as a barrier to continued programme adherence (which, together with uptake, constitute continued access). This barrier was more common among defaulters. All but one of the seven cases citing child's refusal of RUTF as a primary barrier ended in the child defaulting from the programme. Refusal of RUTF was not found to be a barrier in Pakistan. 


\section{Ethiopia}

While most caregivers experienced no problems with children's acceptance of RUTF, several mentioned that their children did not accept RUTF and some would have diarrhoea and vomiting after consuming it. Many of these mothers therefore stopped giving RUTF to their child and stopped attending the programme:

'At first my child had a good appetite. After 5 weeks she refused to eat so I stopped going... She lost her appetite. She didn't even want to see the sachet.' (Beneficiary, defaulter, Ethiopia)

'Unfortunately, when she ate RUTF she started vomiting, so I stopped. I went 2 weeks [to the programme], but completely stopped because of vomiting.' (Beneficiary, defaulter, Ethiopia)

'A main reason for default is the reluctance of mothers: they think that RUTF doesn't work for their child.' (HEW, Ethiopia)

Several caregivers were able to resolve the issue of RUTF acceptance either through their own efforts or with responsive counselling:

'At the initial time, my child was unable to feed, so I tried to boil the RUTF in a small cup. After that, my child became more interested. It became more liquid. She preferred the liquid one. After a few times, she ate even the normal RUTF.' (Beneficiary, recovered, Ethiopia)

'The first time I gave RUTF, he vomited and was less interested even in local foods. Then finally he became adapted to RUTF after 3 days. The health extension workers advised me to prepare complementary feeding and showed how to prepare it with a demonstration.' (Beneficiary, non-responder, Ethiopia)

'At the beginning, my child had diarrhoea [from RUTF]. Then I communicated with health providers and they gave me medication.' (Beneficiary, recovered, Ethiopia)

Some caregivers mentioned that while their child had passed the appetite test administered at the OTP, they were unable to eat a full serving of RUTF at home. Programme staff believed that vomiting and loss of appetite indicated an underlying illness; however, the persistence of this problem suggests that staff knowledge, actions and communications may not have cohered consistently during case management:

'For those who get sick [from RUTF], it could be due to some hidden health problem, but households think it is due to the programme.' (WDA member, Ethiopia)

\section{Discussion}

Barriers to access were similar in both of these wellfunctioning programmes, indicating that households face similar demand-side barriers even when supply-side barriers are minimized. Further, household barriers in these programmes were consistent with findings from other public health programmes, suggesting that many of these barriers were not unique to SAM treatment.

Distance is among the most significant and persistent barriers identified for CMAM programmes ${ }^{(11)}$. This barrier has been found to not only affect other public health programmes, but also to interact with several other common barriers to access. Other studies have supported our finding that gender plays a role in perception of distance, as mediated by purdah restrictions ${ }^{(6)}$. Distance is further affected by seasonality, as demonstrated by challenges to beneficiary access during the rainy season in Pakistan. A study in Niger also found seasonal variation in distancerelated barriers, with longer travel times reported in the wet season than the dry season ${ }^{(25)}$. Finally, the literature indicates an additional interaction between distance and high opportunity costs. While a benchmark of $1 \mathrm{~h}$ travel time has been used in other studies assessing geographic access to health services ${ }^{(26)}$, other studies have found, as we have, a lack of a universally defined 'acceptable' distance to access SAM treatment services ${ }^{(12)}$. In Ethiopia the acceptability of distance to services differed based on the time-intensiveness of other domestic responsibilities such as fetching water and caring for cattle or other family members. Other evidence from rural Ethiopia further highlights the critical implications of distance barriers, showing that children living more than $1.5 \mathrm{~h}$ from a health centre (but not from health posts) have a two to three times greater risk of death than those living closer ${ }^{(27)}$ and that travel time is significantly associated with coverage of important childhood vaccines ${ }^{(28)}$. Both of these Ethiopian studies suggest that households in remote rural areas are more vulnerable to the distance barrier compared with those in more densely populated areas.

While to some extent travel time may be inevitable in remote areas of developing countries, the distance from household to health service can be reduced through engaging community-based staff to deliver services as was done in Ethiopia, or to screen and sensitize households as was done in Pakistan. Evidence shows that reducing the distance barrier, through treatment of SAM directly at the household via community health workers, positively affects beneficiary acceptance of and compliance with services, with implications for early presentation and effective recovery of cases of SAM $^{(13)}$.

Programme uptake is strongly influenced by household opportunity costs across the spectrum of public health services $^{(5,6)}$. Findings from both Pakistan and Ethiopia indicate that caregivers have competing priorities for their time and must balance decisions affecting their child's 
health with their household's welfare and survival. In Tanzania, the poorest households were found to spend over three-quarters of their previous month's expenditure on paediatric hospital admissions ${ }^{(29)}$. Opportunity costs of in-patient SAM treatment are consistently higher than those of community-based services ${ }^{(30,31)}$; the lower cost to households of accessing these community-based services has been identified as a determinant of CMAM programmes' effectiveness and cost-effectiveness ${ }^{(31)}$.

Previous research indicates that low community awareness is among the most common barriers to accessing SAM treatment services ${ }^{(12)}$. In Pakistan, beneficiaries recommended awareness-raising 'in all areas' and scale-up of services 'throughout the whole community', indicating community perceptions that the programme was limited in scope. This was valid to some extent, since this NGOdelivered programme covered only eleven out of sixteen UC in two districts. Further, the programme relied on community nutrition volunteers, whose voluntary status often made it difficult for them to cover and sensitize their entire catchment area. The absence of such recommendations in Ethiopia was due in part to the programme's broad geographic coverage, its integration into national health services and the network of community-based volunteers, formally recognized by the $\mathrm{MoH}$, who were responsible for sensitizing their villages.

While lack of knowledge of services is an important barrier, communities must also understand the relevance of the treatment to their child's condition. Limited public health and education infrastructure in Pakistan restricted the population's ability to perceive potential programme benefits. Other studies have emphasized the connection between education and service uptake ${ }^{(6)}$; however, the extent to which specific health messages can overcome a lack of basic education is not well understood. In underserved communities with limited public infrastructure, a lone CMAM programme will face particular challenges in achieving positive outcomes, due both to environmental factors and limited awareness.

Moreover, regardless of public infrastructure, in some areas cultural beliefs about malnutrition prevailed. There was some evidence in Ethiopia of households suspecting a mother's birth control medication as the cause of malnutrition and seeking treatment from traditional healers. Cultural beliefs are common determinants of care-seeking practices $^{(32)}$. For example, a study in Bangladesh found that households prefer unlicensed health-care providers such as village doctors and traditional healers to other forms of treatment, due in part to the proximity and familiarity of these practitioners ${ }^{(33)}$.

There is some indication that context-specific community-level sensitization mechanisms, potentially including adequately trained and supported community-based health workers, can effectively sensitize communities about existing SAM treatment services, thereby facilitating programme coverage and utilization ${ }^{(14)}$. Sensitization appears to be particularly successful in an integrated programme with high coverage given the regular contact between service providers and community members in such settings ${ }^{(13)}$. Findings from the present study in Ethiopia further support the potential for raising awareness by integrating SAM treatment services within existing community sensitization mechanisms. However, even within this integrated programme, in more remote areas beneficiaries did cite distance barriers. It is therefore possible that even within a scaled-up integrated programme, among remote populations and in areas further from health posts and health centres, beneficiaries have less frequent exposure to, and are therefore less aware of, available services. This indicates an important gap in current mechanisms used to deliver services to remote populations, with implications for equity of service delivery.

Although palatability of RUTF has been identified as a barrier in some programmes, it has not been classified among the top barriers to access in CMAM programmes ${ }^{(12)}$. While child's refusal of RUTF was a commonly cited barrier in Ethiopia, this was not the case in Pakistan. A full investigation of palatability was beyond the scope of the present study, i.e. whether taste or texture was unacceptable to these children or whether loss of appetite was a contributing factor. Two caregivers in Ethiopia specifically mentioned their child disliked the texture of RUTF and two mentioned that the taste was unacceptable; however, these limited data do not indicate a clear trend. Some evidence suggests that RUTF palatability varies according to traditional dietary differences and this remains a subject of debate ${ }^{(34-36)}$. However, given that most caregivers in this setting were able to overcome the barrier of RUTF refusal, particularly after receiving counselling, this issue potentially could be remedied in this setting by reinforced training in administering appetite tests, negotiation skills and improved counselling on proper feeding of RUTF.

These findings suggest that, as with other communitybased programmes, focus should be given to maintaining motivation of community-based staff ${ }^{(37,38)}$. The Ethiopian programme is implemented within national health systems with limited resources. HEW have sixteen different 'packages' of services to deliver, of which SAM treatment is only one. Adding SAM treatment to a health worker's existing workload could potentially result in overburdening, a common challenge in programmes utilizing community-based health workers ${ }^{(37)}$. However, some evidence suggests that adding SAM management to a community health worker's workload does not necessarily result in poor quality of care on other work tasks, provided these workers receive adequate training, supervision and other support ${ }^{(39)}$. In community discussions, community leaders recommended refresher training for HEW and WDA. To ensure continued staff motivation to deliver quality services, ongoing support will be necessary, including refresher training and other incentives, along with setting rational limits on the number and scope of 
tasks and size of catchment area assigned to any one cadre of worker ${ }^{(37,40)}$. Community health workers providing integrated SAM treatment within weak health systems face their own barriers to effectiveness and require support to deliver high-quality care $^{(41)}$. Programme planning should take these considerations into account and allocate adequate resources to support effective service delivery.

\section{Conclusions}

The current study presents a qualitative investigation comparing barriers to access in two SAM treatment services in different countries and with different types of implementing agencies ( $\mathrm{MoH}$ and $\mathrm{NGO}$ ). Findings illustrate that, even within well-functioning programmes, households face a variety of barriers to access, including distance, high opportunity costs and lack of awareness, both of available services and of malnutrition itself. Programmes should aim to minimize these barriers in order to increase access to services.

Previous research has found that several barriers can be mitigated by adjusting service delivery mechanisms. Both programmes presented in the current analysis invested in community-based outreach staff for sensitization. Integration of SAM treatment with other community services appeared to bolster community awareness. However, in more remote areas with less exposure to the intervention, beneficiaries still experienced barriers to remaining in the programme until their children recovered. Further research and policy efforts are needed to investigate feasible mechanisms to reduce the interrelated barriers to access and to ensure equitable delivery of services. This could include a number of possibilities, from doorstep delivery of services to those communities determined to be most vulnerable or at highest risk of default, to investment in cadres of community-based health workers to extend equitable coverage to remote communities.

Integration of SAM treatment with other community-based health and nutrition interventions, as is recommended by the $\mathrm{UN}^{(7)}$, is important in increasing access to life-saving services and strengthening health systems is key to successful integration. However, integration efforts to date have paid inadequate attention to the community component of the health system, including sensitization, mobilization and follow-up. These community-level services will require adequate investment in order to effectively address barriers to access and ensure high and equitable coverage of services.

\section{Acknowledgements}

Acknowledgements: From the Coverage Monitoring Network (CMN), thanks go to Jose Luis Alvarez, Eleanor Rogers and Sophie Woodhead for their assistance in coordination. Additionally, there are several individuals deserving recognition for their time and assistance with the collection of primary data. From Concern Worldwide in Ethiopia and Dublin: Kate Golden, Linda Horgan, Pankaj Kumar, Sosena Mellese, Lulseged Tolla and Charlotte Walford. Special thanks go to Goitom Taddesse from Concern in Mekele for his helpful assistance in coordinating the field work; and to Mussie Alemayehu from Mekele University for his dedicated assistance in translation and data collection. From Action Against Hunger in Pakistan and New York: Cecile Basquin, Charmaine Brett, Shahid Fazal, Maureen Gallagher, Erin Hutchinson and Gaëtan Pietquin. Special thanks go to Dr Asia Khanum, Bheru Lal, and the OTP supervisors and community-level programme staff who took their time to assist with coordination and translation during data collection. Financial support: The study was conducted for the CMN, an inter-agency project funded by the European Commission Directorate-General for Humanitarian Aid and Civil Protection (ECHO) and the US Agency for International Development's (USAID) Office of Foreign Disaster Assistance (OFDA). The funders had no role in the design, analysis or writing of this article. Conflict of interest: None. Authorship: C.P. participated in study design, collected, analysed and interpreted the data, and drafted the manuscript. S.G. participated in study design and coordination, contributed to data interpretation and was involved in drafting the manuscript. Both authors read and approved the final manuscript. Ethics of buman subject participation: Ethical approval was not sought for this analysis as discussion of barriers to accessing nutrition programmes was not considered to constitute a strong risk for harm or disturbance of potential respondents. None the less, informed consent was obtained from all respondents before beginning discussions. Respondents understood the information provided and none refused to participate after receiving this explanation.

\section{Supplementary material}

To view supplementary material for this article, please visit http://dx.doi.org/10.1017/S1368980014002444

\section{References}

1. Victora CG, Hanson K, Bryce J et al. (2004) Achieving universal coverage with health interventions. Lancet 364, 1541-1548.

2. Gwatkin DR, Bhuiya A \& Victora CG (2004) Making health systems more equitable. Lancet 364, 1273-1280.

3. O'Donnell O (2007) Access to health care in developing countries: breaking down demand side barriers. Cad Saude Publica 23, 2820-2834.

4. Jacobs B, Ir P, Bigdeli M et al. (2012) Addressing access barriers to health services: an analytical framework for selecting appropriate interventions in low-income Asian countries. Health Policy Plan 27, 288-300.

5. Peters DH, Garg A, Bloom G et al. (2008) Poverty and access to health care in developing countries. Ann N Y Acad Sci 1136, 161-171.

6. Ensor T \& Cooper S (2004) Overcoming barriers to health service access: influencing the demand side. Health Policy Plan 19, 69-79. 
7. World Health Organization, World Food Programme, United Nations System Standing Committee on Nutrition et al. (2007) Community-Based Management of Severe Acute Malnutrition: A Joint Statement by the World Health Organization, the World Food Programme, the United Nations System Standing Committee on Nutrition and the United Nations Children's Fund. Geneva: WHO/WFP/ UNSCN/UNICEF.

8. Valid International (2006) Community-Based Therapeutic Care (CTC): A Field Manual. Oxford: Valid International.

9. Gatchell V, Forsythe V \& Thomas P (2006) The sustainability of community-based therapeutic care (CTC) in nonemergency contexts. Food Nutr Bull 27, 3 Suppl., S90-S98.

10. Gross R \& Webb P (2006) Wasting time for wasted children: severe child undernutrition must be resolved in nonemergency settings. Lancet 367, 1209-1211.

11. UNICEF, Coverage Monitoring Network \& Action Against Hunger International (2012) The State of Global SAM Management Coverage 2012. New York and London: $\mathrm{UNICEF/CMN/ACF} \mathrm{International.}$

12. Guerrero S, Myatt M \& Collins S (2010) Determinants of coverage in community-based therapeutic care programmes: towards a joint quantitative and qualitative analysis. Disasters 34, 571-585.

13. Puett C, Coates J, Alderman H et al. (2013) Quality of care for severe acute malnutrition delivered by community health workers in southern Bangladesh. Matern Child Nutr 9, 130-142.

14. Sadler K, Puett C, Mothabbir G et al. (2011) Community Case Management of Severe Acute Malnutrition in Southern Bangladesh. Medford, MA: Feinstein International Center, Tufts University.

15. Emergency Nutrition Network (2012) Government Experiences of Scale-Up of Community-Based Management of Acute Malnutrition (CMAM): A Synthesis of Lessons. Addis Ababa: ENN.

16. FDRE Ethiopian Government Portal (2012) Tigray. http:// www.ethiopia.gov.et/statetigray (accessed June 2014).

17. Mammo Kebbede Shenkut (2005) Ethiopia: Where and Who are the World's Illiterates? Paris: UNESCO.

18. Teklehaimanot HD \& Teklehaimanot A (2013) Human resource development for a community-based health extension program: a case study from Ethiopia. Hum Resour Health 11, 39.

19. Weiss AM \& Mughal MAZ (2012) Pakistan. In Berkshire Encyclopedia of Sustainability, vol. 9, pp. 236-240 [L Kotzé and $\mathrm{S}$ Morse, editors]. Great Barrington, MA: Berkshire Publishing.

20. Action Against Hunger (2011) Integrated Rapid Assessment in the Flood Affected Areas of S.F. Rahu/Gholarchi, Dubi, Kario Ganhwar, Trai \& Khorwah Union Councils in West Badin District, Sindh Province, Pakistan. New York: ACF-USA

21. Pakistan Bureau of Statistics (2014) Pakistan Social And Living Standards Measurement Survey 2012-13. Islamabad: PBS.

22. Myatt M, Feleke T, Sadler K et al. (2005) A field trial of a survey method for estimating the coverage of selective feeding programmes. Bull World Health Organ 83, 20-26.

23. Coverage Monitoring Network (2013) SQUEAC Report: Tando Mohammad Khan District, Sindh Province, Pakistan. London: CMN.

24. Saldaña J (2009) The Coding Manual for Qualitative Researchers. London: Sage.
25. Blanford JI, Kumar S, Luo W et al. (2012) It's a long, long walk: accessibility to hospitals, maternity and integrated health centers in Niger. Int J Health Geogr 11, 24.

26. Noor AM, Amin AA, Gething PW et al. (2006) Modelling distances travelled to government health services in Kenya. Trop Med Int Health 11, 188-196.

27. Okwaraji YB, Cousens S, Berhane Y et al. (2012) Effect of geographical access to health facilities on child mortality in rural Ethiopia: a community based cross sectional study. PLoS One 7, e33564.

28. Okwaraji YB, Mulholland K, Schellenberg JR et al. (2012) The association between travel time to health facilities and childhood vaccine coverage in rural Ethiopia. a community based cross sectional study. BMC Public Health 12, 476.

29. Saksena P, Reyburn H, Njau B et al. (2010) Patient costs for paediatric hospital admissions in Tanzania: a neglected burden? Health Policy Plan 25, 328-333.

30. Tekeste A, Wondafrash M, Azene G et al. (2012) Cost effectiveness of community-based and in-patient therapeutic feeding programs to treat severe acute malnutrition in Ethiopia. Cost Eff Resour Alloc 10, 4.

31. Puett C, Sadler K, Alderman H et al. (2013) Costeffectiveness of the community-based management of severe acute malnutrition by community health workers in southern Bangladesh. Health Policy Plan 28, 386-399.

32. Colvin CJ, Smith HJ, Swartz A et al. (2013) Understanding careseeking for child illness in sub-Saharan Africa: a systematic review and conceptual framework based on qualitative research of household recognition and response to child diarrhoea, pneumonia and malaria. Soc Sci Med 86, 66-78.

33. Ahmed NU, Alam MM, Sultana F et al. (2006) Reaching the unreachable: barriers of the poorest to accessing NGO healthcare services in Bangladesh. J Health Popul Nutr 24, 456-466.

34. Ali E, Zachariah R, Dahmane A et al. (2013) Peanut-based ready-to-use therapeutic food: acceptability among malnourished children and community workers in Bangladesh. Public Health Action 3, 128-135.

35. Bourdier F (2009) Socio-Anthropological Investigation Related to the Acceptability of Plumpy'nut in Cambodia. Paris: Institut de Recherche pour le Développement.

36. Nga TT, Nguyen M, Mathisen R et al. (2013) Acceptability and impact on anthropometry of a locally developed readyto-use therapeutic food in pre-school children in Vietnam. Nutr J 12, 120.

37. Bhattacharyya K, Winch PJ, LeBan K et al. (2001) Community Health Worker Incentives and Disincentives: How They Affect Motivation, Retention and Sustainability. Arlington, VA: BASICS II.

38. Pallas SW, Minhas D, Pérez-Escamilla R et al. (2013) Community health workers in low-and middle-income countries: what do we know about scaling up and sustainability? Am J Public Health 103, e74-e82.

39. Puett C, Coates J, Alderman H et al. (2012) Does greater workload lead to reduced quality of preventive and curative care among community health workers in Bangladesh? Food Nutr Bull 33, 273-287.

40. Phillips M, Zachariah R \& Venis S (2008) Task shifting for antiretroviral treatment delivery in sub-Saharan Africa: not a panacea. Lancet 371, 682-684.

41. Puett C, Alderman H, Sadler K et al. (2013) 'Sometimes they fail to keep their faith in us': community health worker perceptions of structural barriers to quality of care and community utilisation of services in Bangladesh. Matern Child Nutr (Epublication ahead of print version). 